\title{
$\nabla$ \\ Garbhasanskara (The Prenatal Stimulation): Educating Mother as Well as Baby
}

\section{IJCRR}

Section: Healthcare

Sci. Journal Impact

Factor: 6.1 (2018)

ICV: 90.90 (2018)

Scopus'

\section{Priya P. Chawle ${ }^{1}$, Bhagyashree Chaudhari ${ }^{2}$, Varsha Adhav ${ }^{3}$, Mugdha L. Junghari ${ }^{4}$, Harshala Sharma ${ }^{5}$}

\begin{abstract}
'Assistant Professor, Department of Prasutitantra and Striroga, DMACH\&RC, Nagpur; ${ }^{2}$ Assistant Professor, Department of Prasutitantra and Striroga, MGACH\&RC, Salod (H), Wardha; ${ }^{3}$ Associate Professor, Department of Prasutitantra and Striroga, DMACH\&RC, Nagpur; ${ }^{4}$ Associate Professor, Department of Obstetrics and Gynaecology, Datta Meghe Medical College, SMHRC Datta Meghe lnstitute of Medical Sciences,

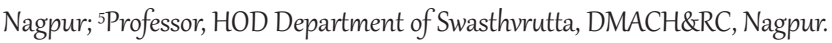

\section{ABSTRACT}

The privilege of recreating life is the most wonderful thing women have got. With this precious gift, like the other side of coin big hurdles comes in her life with the state of pregnancy. It is difficult to get adjusted. And moreover, it is difficult for many women to accept the would be coming new life. And get prepared for him or her. Most of them are unknown from the ability of unborn baby's brain growth. The unborn baby's brain consequently our personalities emerge from the complex interplay between the genes we are born with and the experience we have. Research has confirmed that more than $60 \%$ of the baby's brain growth occurs in the intrauterine stage, on this basis it can be concluded that Garbhasanskara i.e. Educating unborn baby is more essential than schooling. Which can be done with the different modalities of garbhasanskara. It is going to contribute to making the personality of the unborn baby which is ultimately contribute to making a good human being.

Key Words: Pregnancy, Garbhasanskara, Prenatal stimulation, Fetal psychology, Yoga in pregnancy

\section{INTRODUCTION}

Women are gifted with the privilege of pregnancy. It is the precious phase which most of the women want to go through. It is good to have a pregnancy by choice that makes women possess positive attitude toward pregnancy and baby. Carrying life in her body brings the sense of happiness but she has to face lot physical and mental disturbances for first time in her life. pregnancy is literally a roller coaster of totally new things that brings joy, feeling of completeness at the same time anxiety, fear, insecurities about her carrier, change in body shape, sleep disturbances, restlessness. These things ultimately going to affect fetus, endocrine systemand mineral abnormality in mothers ${ }^{1,2}$. fetal psychology is depend on hormonal and psychological changes in mother. Maternal feelings and moods are linked to hormone and neurotransmitters that travel through the bloodstream and across placenta to the developing brain of the unborn child. Prolonged exposure to stress hormones including adrenaline and cortisol, prime the growing brain to react in fight-or-flight mode throughout life. On other hand maternal emphasis on joy and love bathes the growing brain in "feel good" endorphins and neurohormones such as oxytocin, promoting a lifelong sense of well-being. Starting from the moment of conception, a child's brain is wired by its environment provided by mother ${ }^{3}$

The fetal environment can be altered if stress in the mother changes her hormonal profile, hypertension is the commonest medical emergency encountered during pregnancy which is a stressful factor for both mother and fetus ${ }^{4}$. Preeclampsia is associated with substantial risks for the fetus and the mother. ${ }^{5}$ There is a clear link between the maternal and fetal levels of cortisol in humans. However, there are still many difficulties in understanding the processes involved in the interaction. The hyperresponsive HPA axis may have evolved during evolution in a demanding environment, but today it remains at the cost of susceptibility to neurodevelopmental disorders ${ }^{6}$. Maternal stress causes poor outcome pregnancy $\&$ results in early programming of brain functions with permanent changes in neuroendocrine regulation and behavior in offspring. ${ }^{2,7}$ Structural level too like preterm labour, postdatism which is increased perinatal complications including fetal distress and meconium aspiration syndrome are linked with this. Mother and fetus complications are seen in postdated pregnancies. ${ }^{8}$

\section{Corresponding Author:}

Dr. Bhagyashree Chaudhari, Assistant Professor, Department of Prasutitantra and Striroga, MGACH \& RC, Salod (H), Wardha

ISSN: 2231-2196 (Print)

Received: 27.05 .2020
ISSN: 0975-5241 (Online)

Revised: 20.06 .2020
Accepted: 02.07 .2020
Published: 21.07.2020 
On the basis of this concept, it is understood that because of stress and anxiety the future child will suffer mentally \& emotionally. For the sake of reducing the risk factor and to give the possible best outcome of pregnancy at psychological and structural level, various practices are suggested under the name of garbhasanskara i.e. the prenatal stimulation. It is the try of giving good environment for a growing fetus due to which one can get the baby with good virtue. For the better future of society garbhasanskara is the need of the hour. These practices should get applied to each and every ANC clinic.

\section{Need of study}

Parenting is the concept which starts right from conception. Pregnant women's psychological health has consequences for fetal neurobehavioural environment so as on fetal outcome. There is huge role of women' mental health on child's development during prenatal and postnatal period. ${ }^{9}$

There is awareness of pregnancy disorders like gestational diabetes, hypothyroidism, structural anomalies, etc, but there is less awareness of depression during pregnancy and very less obstetricians have the concern of pregnancy depression in routine obstetric consultation. By giving proper consultation and teaching to mother it is possible to create good virtue child which will help ultimately to build a great society. So the need for change is seeking here, for that matter this review is made.

\section{Aims and Objectives}

Aims: To educate pregnant women and their unborn babies through their mother.

\section{Objectives:}

1) To create the baby with intelligence, emotionally stable, socially aware, good valued, and virtue.

2) To relieve maternal anxiety, stress.

3) To educate the pregnant woman about pregnancy and delivery to avoid unnecessary panic about the changes happening with her body and mind.

\section{MATERIAL \& METHOD}

There are different aspects of garbhasanskara which comes under garbhasanskara practices. Which includes counselling, meditation, yoga, pranayama, ahara, womb talking, Music therapy.

Counselling: Pregnancy counselling is necessary. Once she gets pregnant carries a bundle of queries. She should get cleared with the vulnerability of myths and facts. Proper knowledge about handling the changes in her body and mind is to be given.

\section{Yoga and pranayama in pregnancy}

Yoga is defined as a mind-body practice that included traditional physical postures and may incorporate other components, such as breathing exercises and meditation. Yoga is a low impact, easily modifiable, and mindful activity, considering it is a safe and sustainable activity for pregnant women. Prenatal yoga opens the door for expectant mothers to develop a connection with her body, mind, and unborn baby Pregnant women demonstrated reductions in psychological tension, heart rate, skin conductance, respiration, and cortisol levels, and increased respiratory sinus arrhythmia. The degrees to which these were elicited by the guided imagery relaxation manipulation per se, as opposed to simple rest and/or recumbency ${ }^{10}$

[Narendran et al.] yoga practices including physical postures, breathing, and meditation Practiced by pregnant women $1 \mathrm{~h}$ a day resulted in a rise in birth weight, a decrease in premature labor and a decrease in IUGR, either in isolation or in PIHrelated circumstances, without any increased complications. [Beddoe et al.] found that women practicing yoga in their second trimester reported significant reductions in physical pain from baseline to post-intervention. Women in their third trimester showed greater reductions in perceived stress and trait anxiety. From this, it is clear that yoga can be used to prevent or reduce obstetric complications. ${ }^{11}$ Yoga works like other self-relieving methods, like meditation, relaxation, and exercise. Yoga tends to modulate stress response processes by raising perceived stress and anxiety. It, in effect, decreases physiological anticipation, e.g. reduces heart rate, lowers blood pressure, and eases breathing. There is also evidence that yoga practices help improve the variability of the heart rate, a measure of the capacity of the body to respond more flexibly to stress. ${ }^{12}$

Meditation: Mindful meditation is very important it release accumulated stress, increases energy level and improves health. Maternal stress is the reason for various pregnancy complications like PIH, eclampsia, gestational diabetes, lbw babies, preterm labour. Even maternal stress can affect upcoming babies' emotional, behavioural \& cognitive functions. Even can lead to psychiatric disorders in child. The study shows that the cord blood cortisol level was lower in the babies of mother who meditate that the mothers who didn't meditate. Meditation brings calmness, helps her to get relax and happy. It is proved that meditation has a positive effect on baby's temperament. ${ }^{13}$

Ahara( diet): Diet plays a very important role in pregnancy. In Ayurveda texts, it is said that utpatti of manah is from diet 'Annamayamanah' i.e. that woman's temperament is dependent on ahara (diet). It is said to avoid tamasik and rajasikaahara in order to perceive satwikguna in the baby through mother. Whatever the mother eats goes to baby through maternal blood. By the modern point of view for 
Growing baby mother should have to take a proper balanced diet to fulfill the extra needs of macro and micronutrients for proper growth.

Music therapy in pregnancy: Music is often tagged as a perfect tool to strengthen mother-child bonding. The fact that infants recognize music and particularly the mother's singing voice (Cevasco, 2008) from their intrauterine times gives rise to music psychological questions. Fetal learning mechanisms and neural brain development are closely interrelated. Positive auditory experience is considered essential for early brain maturation and a potential contributing factor for healthy neurodevelopment (McMahon, Wintermark, \& Lahav, 2012). ${ }^{14}$

Garbhasanvada (womb talking): de Casper work suggests, fetal brain primed for language in the womb. That explains why at the age of four days, infants can distinguish language from other sounds and begin to prefer not just their mother's voice but also their mother's language. Observation of newborns clears the above statement. Soon after birth babies, preferentially select speech sound over the other sound they seem to grasp intuitively the meaning of intonation and rhythm in speech, even when they do not understand the words. On this basis, it is clear that the baby can hear. the pregnant women got the privilege of communicating with the baby even before seeing him or her. The message for pregnant ladies is that their babies are listening and learning and remembering during pregnancy. It is good news that the expecting mother can tell the good virtue \& can work on imbibing good qualities in their child.

\section{DISCUSSION}

In the era of $21^{\text {st }}$ century, everyone wants baby endowed with good values \& virtues. 'Eugenics' the study of possibilities of improving the qualities of human species. The concept of eugenics supports garbhasanskara. SanskritGarbha refers fetus in the womb and Sanskara refer to educating the mind. So Garbhasanskar basically refers to the development of the brain of the fetus. The recent studies shows that epigenetics plays a big role in the psychosocial development of the baby. The surrounding of the baby which is provided by the mother plays an important role in his mental development. For baby, womb is the ultimate best place to learn. Mother's diet, thoughts, temperament, behaviour, habits are going to make an impact on the baby's mind and body. it is essential to give proper planned education to the baby through appropriate stimuli. it is to be done through mother only. The concept belongs to not only the baby but also to the mother. Education mother by totally different aspect. Traditionally it is assumed that value-based parenting starts from the conception that is why members in the family speak about the significance of positive thoughts and feeling during pregnancy.
Garbhasanskar has developed and accepted due to its scientific fact that proves its significance and importance in the growth of a child. Research has confirmed that more than $60 \%$ of the baby's brain growth occurs in the intrauterine stage. Further studies have revealed that an unborn baby has the capability to pay attention and reply to outside stimuli.

Researches prove that even in the womb the baby recognizes, understands, hears, listens, and feels, perceived his mother's attachment. Communicating with the baby is an important part of Garbhasanskara. 'Sanskaro hi gunantaradhanam' that means by stimulation \& sensitisation one can imbibe good virtues in the baby. Special techniques such as positive thinking, guided meditation, visualizing, music therapy, relaxation are used to create this communication with baby. The way of communicating baby can be through narration of good stories, good values, good mu$\mathrm{sic}^{4}$. Meditation plays an important role to get connected to baby soulfully. That makes the fetus more susceptible to pursue new things easily as the connection is built already. Yoga in pregnancy is beneficial for the mothers to get rid of minor ailments like backache. Yoga facilitates the stretching, toning, proper movements and improves strength of pelvic floor muscles so as to make easy delivery of the baby. And it gives strength to that lady to go through the painful process of labour. Singing is one of the best ways of bonding and love. Through singing, connective consciousness extends to their unborn babies. ${ }^{3}$

The motive of garbhasanskara is to create a healthy, happy, good virtue, well cultured, intelligent, and blissful child. At the same time to reduce maternal stress, anxiety, worry, and make her comfortable and optimistic toward her state of pregnancy so that she can enjoy her womanhood and motherhood without hurdles.

\section{CONCLUSION}

It is to be concluded that garbhasanskra and eugenics holds extra ordinary importance in today's obstetric practices. Suitable attention to psycho-neuro-endocrinological issues may be helpful for obstetrician to gain a more precise and holistic understanding of patients and will thus rises the chances of providing the most appropriate treatment. ${ }^{1,16}$ It is a blissful fact that one can make the valuable changes in their unborn baby by practicing above said things on their own. Garbhasanskara practices are the way of making the world a better and peaceful place to recede.

\section{Acknowledgement: None}

Conflict of interest: None

Financial support: None 


\section{REFERENCES}

1. Ranjit S. Ambad, Lata Kanyal Butola, Brij Raj Singh, Nandkishor Bankar, Ajinkya S. Ghogare, Ragini Patil. A cross-sectional comparison of minerals in psychiatric disorder. International Journal of Psychosocial Rehabilitation, Vol. 24, Issue 06, 2020; page No 5968-5976.

2. Ranjit S. Ambad, Rakesh Kumar Jha, Nandkishor Bankar, Dr. Brij Raj Singh, Dr. Ajinkya S. Ghogare, Dr. Ragini Patil. Role of prolactin and thyroid hormone in psychiatric disorders. International Journal of Psychosocial Rehabilitation, Vol. 24, Issue 06, 2020 page no 6001-6005.

3. Thomas R. Verny, Pamela Weintraub Book: Pre- parenting nurturing your child from conception, SIMON \& SCHUSTER.

4. E.J.H Mulder ${ }^{\mathrm{a}}$ P.G Roblesde Medina ${ }^{\mathrm{a}}$ A.CHuizink ${ }^{\mathrm{b}}$ B.R.HVan den Bergh ${ }^{c}$ J.K Buitelaar ${ }^{\mathrm{b}}$ G.H.AVisser ${ }^{\mathrm{a}}$, Prenatal maternal stress: effects on pregnancy and the (unborn) child.

5. Nicole M. Talge, Charles Neal, Vivette Glover the Early Stress, Translational Research and Prevention Science Network: Fetal and Neonatal Experience on Child and Adolescent Mental Health Antenatal maternal stress and long-term effects on child neurodevelopment: how and why?First published:07 March 2007 https://doi.org/10.1111/j.1469-7610.2006.01714.x.

6. Poudevigne, M.S., O'Connor, P.J. A Review of Physical Activity Patterns in Pregnant Women and Their Relationship to Psychological Health. Sports Med 36, 19-38 (2006). https://doi. org/10.2165/00007256-200636010-00003.

7. Janet A. DiPietro, Kathleen A. Costigan, Priscilla Nelson, Edith D. Gurewitsch, Mark L. Laudenslager, Fetal responses to induced maternal relaxation during pregnancy ,Biol Psychol. Author manuscript; available in PMC 2009 Jan 1.Published in final edited form as: Biol Psychol. 2008 Jan; 77(1): 11-19. Published online 2007 Aug 31. doi: 10.1016/j.biopsycho.2007.08.008

8. Michael T. Kinsella, B.A., Catherine Monk, Impact of Maternal Stress, Depression \& Anxiety on Fetal Neurobehavioral DevelopmentPublished in final edited form as: Clin Obstet Gynecol. 2009 Sep; 52(3): 425-440.

9. Qinxian Jiang, Zhengguo Wu, Li Zhou, Jenae Dunlop, Peijie Chen, Effects of Yoga Intervention during Pregnancy: A Review for Current Status, 1Key Laboratory of Exercise and
Health Sciences of the Ministry of Education, Shanghai University of Sport, Shanghai, China Department of Physical Education, Changzhi University, Changzhi, China 3Department of Kinesiology, Xi' an Physical Education University, Xi'an, China 4Department Speech and Hearing Sciences, Portland State University, Portland, Oregon Am J Perinatol 2015;32:503-514.

10. Mrs. Pallavi Sengupta, Health Impacts of Yoga and Pranayama: A State-of-the-Art Review Department of Physiology, Vidyasagar College for Women, University of Calcutta, 39, Sankar Ghosh Lane, Kolkata 700 006, West Bengal, India. E-mail: ni. oc.oohay@4891_vallap_ynnus, 2012 Jul; 3(7): 444-458.

11. Wolfgang Mastnak, Perinatal Music Therapy and Antenatal Music Classes: Principles, Mechanisms, and Benefits, 2016; 25(3): 184-192.

12. Puja saini, benefits of meditation during pregnancy, 5 august 2018 (Google Scholar)..

13. Mrs. Jyotsna Rajendra Deshpande, a study to assess the effect of selected aspects of garbhasanskar on stress coping strategies and wellbeing of antenatal mothers of punecity.Under the guidance of drvishal G. jadhav, May 2016.

14. Bhriegu, R., M. Agrawal, and C. Hariharan. "Assessment of Maternal and Perinatal Outcome in Postdated Pregnancy." Journal of Datta Meghe Institute of Medical Sciences University 12, no. 1 (2017): 35-40. https://doi.org/10.4103/jdmimsu.jdmimsu_20_17.

15. Gaikwad, K.B., N.G. Joshi, and S.P. Selkar. "Study of Nitrosative Stress in 'Pregnancy Induced Hypertension."' Journal of Clinical and Diagnostic Research 11, no. 3 (2017): BC06-8.

16. Yadav, S., M. Agrawal, C. Hariharan, D. Dewani, K. Vadera, and N. Krishna. "A Comparative Study of Serum Lipid Profile of Women with Preeclampsia and Normotensive Pregnancy.” Journal of Datta Meghe Institute of Medical SciencesUniversity 13, no. 2 (2018): 83-86.

17. Dr. Ranjit S. Ambad, Roshan Kumar Jha, Dr. Nandkishor Bankar, Dr. Brij Raj Singh, Dr. Ajinkya S. Ghogare, Dr. Ragini Patil. A cross-sectional comparison of serum hormone (fsh, tsh, gh) concentrations in untreated patients with psychiatric disorder. International Journal of Psychosocial Rehabilitation, Vol. 24, Issue 06, 2020 page no. 5960-5967. 